[Disclaimer: This report was commissioned and will be published by the Social Sciences and Humanities Research Council of Canada. The content of the report represents the views of the authors and not necessarily those of the research council.]

\title{
Trends in Peer Review
}

Synthesis Paper for the Social Sciences and Humanities Research Council and the Natural Sciences and Engineering Research Council of Canada

\author{
Martin Reinhart \\ Humboldt-Universität zu Berlin \\ martin.reinhart@hu-berlin.de \\ Cornelia Schendzielorz \\ Humboldt-Universität zu Berlin \\ schendzc@hu-berlin.de
}

\section{S UMMARY}

Peer review is primarily discussed in the literature with respect to its deficits, e.g. bias or inefficiency. In contrast, our synthesis asks why peer review is used ubiquitously and why it works despite such deficits. Historically, one answer lies in peer review not just providing expertise-based decisions on scientific resources (publication space, funding, jobs), but also providing an organized procedure to give these decisions legitimacy outside of science, e.g. in politics. The current situation is marked by a landscape of national and international funding and review activities that not only complement each other, but overlap, mirror, or rival each other. The current challenge rests in 
adapting peer review to different funding programmes within this landscape and without adding unnecessary burden on researchers and research organisations. To capture these aspects of scientific self-governance, we suggest an alternative conception of grant peer review that allows for thinking about peer review procedures as made up of different elements. Our key findings from such a conception are the following:

o Peer review procedures have become more complex and formalized, as a result of being adapted to the different settings in publishing, funding, and hiring, on the national and international level.

o The diversity and ubiquity of peer review rests upon its adaptability and scalability in reaching the 'right' decisions, i.e. based on scientific exellence, as well as in producing legitimate decisions, i.e. accepted by multiple stakeholders.

o Peer review can be partitioned into eight elemental practices: four essential practices - postulating, consultative, decisive, and administrative - and another four - debating, presenting, observing, and moderating - that provide further combinatorial possibilities.

o Through context-specific combinations of these elemental practices into a procedure, peer review generates legitimacy for judgements on scientific quality, inside and outside of science.

o Peer review should not be seen as a 'measurement device' for scientific quality. Its diversity attests to the fact that issues of quality and legitimacy are intertwined and should be addressed openly.

o Peer review procedures can act as laboratories for deliberation where the robustness and validity of research are equally relevant issues as participation, representation, accountability, or legibility; in effect, allowing for experiments and innovations in science policy.

\section{IN TRODUCTION}

It is striking how different research fields and disciplines can be in how they produce knowledge, e.g. by experimenting, by simulating, or by surveying. Despite these disciplinary differences, however, expert reviewing of knowledge claims is ubiquitous, e.g. in publishing, in funding, or in hiring. Whether it is called peer review, merit review, expert review, peer evaluation, or something else, using reviewing procedures to ground important decisions has become a self-evident expectation; such decisions also have become more frequent, as the reliance on grants and third-party funding has increased in 
science. Peer review has not just become ubiquitous but also more diverse and increasingly formalized. Peer review procedures come in many variations, some with external reviewing, some with an expert panel, some with presentations by applicants, some even with a lottery element. With this growth and variation, procedures also have become more complex and formalized, with some containing an intricate series of decision steps, some having detailed criteria with fine-grained rating scales, and some even being regulated through national policies and law. In short, peer review is a success story because it has been adapted to ground decisions on scientific resources in many different settings.

The literature on peer review has reflected little on the question why peer review works and more on why it works badly or does not work at all. A large number of studies have attempted to show that peer review is biased, unreliable, or invalid. Gender bias, disagreements between reviewers, or rejections of ultimately Nobel prize winning work, have all been shown to occur and are the source of arguments for (fundamental) reform or sometimes for complete abolishment of peer review. Much of the research on peer review suffers from very limited access to relevant data and, thus, mostly follows a case-study type research design. As a result, it remains difficult to assess the validity of these individual results, which are based in, what we call, a deficit model of peer review. The most conspicuous and reliably repeated result from this literature is that much of the chance for acceptance or rejection of an application, a manuscript, or a proposal rests on factors in the selection of reviewers that have nothing to do with their expertise. What most commentators have drawn from these results is that these deficits should be eliminated to ensure that peer review reliably and validly identifies the best research. This is, however, a one-sided view, as peer review is mainly seen as a measurement device to identify scientific quality to determine publication or funding decisions. It neglects the diversity and ubiquity of the phenomenon of peer review, which we see as an indication that it does more than just identify the best research, but provides a procedure to reach decisions on scientific resources in situations where there are multiple requirements, not just scientific excellence. Such as shift in perspective is also warranted, because it has become questionable whether it is even possible to identify excellence in grant peer review (Van den Besselaar \& Sandtröm 2015).

In contrast to much of the literature, our report is based on the premise that we should explain how peer review works, despite these deficits. Such a view can start with noting that the many criticisms of peer review are a result of 
the increasing importance of peer review. As a result of the relative growth of third-party funding and the more frequent use of evaluations in science, the success of institutions, individual researchers, and research programmes is increasingly decided in peer review, and peer review, thus, receives more scrutiny. Such a view can also start by noting that the history of peer review gives strong indication that the need to implement and expand peer review arose as much in the context of scientific journals vetting manuscripts as in the context of science policy legitimizing public spending for research. Peer review only became ubiquitous and generally agreed upon as a result of political debates starting in the 1960s that questioned increasing public research budgets. Our most basic claim for this report is, thus, that peer review is a flexible procedure that is used in a variety of constellations where decisions must be reached that balance scientific and political requirements. The success, i.e. the ubiquitous use, of peer review is as much predicated on its ability to reach the right decisions, i.e. based on scientific exellence, as on its ability to produce legitimate decisions, i.e. accepted by multiple stakeholders. It is this second aspect, the ways how peer review produces legitimacy procedurally, that will be emphasized in this report.

\section{BACKGROUND}

The practice of reviewing scientific knowledge claims has a long and varied history. Most commonly referred to, currently, as peer review, the practice dates back at least to the $17^{\text {th }}$ century, where it already served two separate purposes. The historic developments associated with the Age of Enlightenment and what has become known as the Scientific Revolution, produced an epistemic and a political problem for claims to new knowledge. In light of the weakening of church and tradition as arbiters of knowledge, the epistemic problem revolved around the question who could be trusted as a reliable source of knowledge, when, in principal, every individual should be able to "read from the book of nature" (Shapin \& Schaffer 1985). The political problem revolved around the question, who could be trusted with possibly dangerous new knowledge, when political authorities were no longer capable of controlling printed communication through censorship (Biagioli 2002). What became the social innovation to solve both problems were practices of reviewing knowledge claims within scholarly societies.

The reviewing practices from the $17^{\text {th }}$ century, e.g. at the Royal Society in London, may seem outdated, aristocratic, and generally not relevant for how 
peer review should work in the present context of publically funded research and pervasive digital technology. Verifying knowledge claims happened as part of a network of communication through letters, with the secretary of the society deciding on what should be read at meetings, or by fellows performing new experiments, for their peers to be witnesses (Zuckerman \& Merton 1971, Shapin 1994). Ensuring trust in the safety of new knowledge happened by staging spectacular experiments in public (Shapin \& Schaffer 1985), or in signing a contract with political authorities to be exempt from censorship, as was the case for the invisible college of british natural philosophers when they were granted a royal charter in 1660 to become the Royal Society (Biagioli 2002). While the details of these practices and how they have evolved over time maybe of a purely historical interest, there is at least one overarching question that is relevant for how we deal with peer review in the present: In light of its history, what makes reviewing practices special, for them to work as elements in the (self-)governance of science in such vastly different contexts? They were used across time, as mentioned, but they are now common in such diverse organizational contexts as journals, funding organizations, or universities, and are seen as adequate in all disciplines, despite their large differences otherwise (Becher \& Trowler 2001). Our claim is that the central role and the widespread use of peer review are due to its ability to resolve epistemic and political issues in science simultaneously.

The most telling moment in the history of peer review is pinpointed by Melinda Baldwin (2018) in the 1960s and 1970s in US-american politics: She compares two controversies in science policy; in 1962 concerns were raised about the possible mismanagement of funds at the National Institutes of Health (NIH) and in 1975 congressmen questioned whether the National Science Foundation's (NSF) budget was used to fund research that was not in the interest of the american people. Both cases led to investigations by political oversight committees with the stark difference that in the 1960s the term peer review and the practice of external reviewing of grant application were practically unheard of, while in the 1970s the term peer review was not only taken for granted but the move to more external reviewing became the solution to ensure more public accountability. This marks the point in history when peer review is thought of as the default procedure through which most decisions on scarce scientific resources are made, because it satisfies the need for decisions to be based on scientific quality and the need for decisions to be legitimate in a wider societal context. 
What this history can illustrate is that peer review is adaptable and scalable for purposes internal to science as well as external to it. Internally it has been adapted to every emerging field or discipline and, despite the differences among the disciplines, has formed the backbone of an institutional structure that allows for the self-governance of science. Externally it has been adapted to various demands for accountability in changing societal contexts. We need not think of these contexts as primarily political. A recent example for calls for peer review from a variety of societal stakeholders occured during the Covid-19 pandemic, when the quality of preprints became a publically debated issue. Nonetheless, the specific political context is of importance because of the history of science funding after the 'Baldwin moments. The time up to the present is characterized by significant growth in science funding, by a discernible shift from block funding to project-based funding, by the formation of national and international fields of science policy, and a corresponding growth and differentiation of peer review procedures. This connected expansion of science funding, science policy, and peer review has led to emerging new issues in the present: a landscape of national and international funding and review activities that not only complement each other, but overlap, mirror, or rival each other. Here, the adaptability of peer review to different funding programmes produces an increasing burden on individual researchers and research organisations, who work on keeping a profile that maximises their chances not just in one programme but in as many as possible. This can become a balancing act, when the review procedures differ markedly, or when careers are made to conform to the funding criteria of a sequence of career funding programmes.

While such emerging issues have not yet been addressed by peer review research, the strenghts and, especially, the weaknesses of individual peer review procedures are the topic of a large number of studies (e.g. Neufeld et al. 2013). We refrain from discussing the evidence from these studies extensively, as there are a sizeable number of reviews available (we draw from Guthrie et al. 2017 for this section, as its focus is on grant peer review). "The strongest evidence $[. .$.$] indicates a bias against innovative research. There is also$ fairly clear evidence that peer review is, at best, a weak predictor of future research performance, and that ratings vary considerably between reviewers. There is some evidence of age bias and cronyism" (Guthrie et al. 2017: 1). These deficits are also part of the clear evidence that peer review involves a significant element of contingency, in that chances of success for individual applications are also determined by random aspects in the selection of quali- 
fied reviewers (the classic study is Cole et al. 1981). Newer research has also begun to address the effort that is spent for review procedures: "Good evidence shows that the burden of peer review is high and that around $75 \%$ of it falls on applicants. By contrast, many of the efforts to reduce burden are focused on funders and reviewers/panel members" (Guthrie et al. 2017: 1).

While a research focus on the efficiency of peer review (burden, effort, cost) is relatively new, research on the effectiveness (bias, reliability, validity) has merely changed over the last 40 years. The evidence reported by Guthrie et al. in 2017 has progressed little from what the state of evidence was 20 years earlier; and that in itself is a relevant fact about peer review. Despite much of the literature using a primarily evaluative framework - i.e. asking about effectiveness and efficiency to improve peer review - this seems to have had little effect on the practice of peer review. Some bias, low agreement between reviewers, and questionable validity have remained the deplored deficits of peer review over time. This is not to say that providing this evidence had no effect on practice, when some measures have clearly been justified by recourse to such evidence, e.g. the increased use of panels to improve reliability, or supporting decisions by performance indicators. What is equally clear, however, is, first, that measures to mitigate one deficit have had unintended consequences in exacerbating other deficits. It seems, e.g., that improved reliability from panels comes at the cost of more cronyism or that perfomance indicators have introduced new biases that applicants try to exploit by 'gaming the indicators. Second, and more importantly, it has become clear that pressure to change peer review procedures comes less from evidence of its deficiencies than from the demand to use it in more and more diverse settings. That demand can come from new funding programmes, such as the 'excellence initiatives' in multiple countries (e.g. Germany or France) or from national evaluation systems for research performance, such as the Research Excellence Framework in Great Britain.

We see the current state of evidence and the ongoing debates as validation for the historical insight that peer review is an adaptable and scalable procedure for purposes internal to science as well as external to it. It can be seen as a measurement device for scientific quality, but such a view must be embedded in (political) aspects of legitimacy, which, at its most simplistic, boil down to everyday arguments about justifying public expediture for science. We suggest, as a consequence, to view peer review not just as a procedure for deciding on scarce resources, situated in organizations such as funders, journals, or universities, but as an arena in which general issues about scientific quality 
and legitimacy are negotiated. In this arena the robustness or validity of research are equally relevant issues as participation, representation, accountability, or legibility (Rosanvallon 2018), which are frequently seen as nonscientific, political, and, thus, secondary. What such a view allows, is to address the overarching trends in peer review - formalization and increasing complexity of procedures, adoption and imitation of procedures across organisations and national contexts - as ways of justifying science spending, and science itself, in societal contexts where the role of science has become central and, thus, also politicized. What such a view also allows is to frame peer review and especially the organizations that organize and implement peer review procedures as laboratories for deliberation, where experiments and innovations in how quality and legitimacy relate to each other can take place.

\section{OVERVIEW OF EXISTING PEER REVIEW FORMATS}

Since there is no readily available classification of peer review types, we will give an overview of existing peer review formats in two steps. To address the variety of peer review procedures and the range of their use we, first, give an overview of the context in which peer review is used in public research funding and, then, second, present the variety of peer review procedures within these contexts. We will need, also, to provide some background on the structure of research funding by outlining some formative principles of the national and supranational research funding landscape. In line with the request from the Canadian Research Councils, we mainly use examples from the European funding landscape, as they might be less familiar in North America and could, thus, provide more inspiration.

For the context of funding peer review, a first notable organizing principle follows the distinction between career funding and project funding. While one funding agency may focus career stages such as phd-grants, early career researcher grants or senior researcher grants, others differentiate along the size of research projects, providing on the one hand grants for single projects and on the other hand for collaborative research consortia comprising several subprojects. In addition or even in combination with both organizing principles, we also find funding schemes distinguishing the addressees of the funding, be it a single researcher in personal grants or in fellowship programs, be it a research consortium, cluster or alliance, e.g. in large scale programs and initiatives to foster research and innovation. The simple distinctions become 
increasingly complex when they are adopted and combined on the level of national and supranational funding systems; especially in how elements of different principles relate to each other nationally and then intersect with supranational funding, for which the European Union and the numerous national funding characteristics across Europe are a prime example.

The most prominent funding programmes for individual careers on the supranational level are the "Starting Grant", "Consolidator Grant", and "Advanced Grant" by the European Research Council. All of them comparatively well endowed, with high rejection rates ( $\sim 90 \%)$, and high reputation. In addition, the Marie-Skłodowska-Curie Actions, equally competitive and prestigious, offer a set of fellowships and programmes for career development. They are part of the Framework Programme for Research and Technological Development, currently called Horizon 2020. This framework also provides a high amount of funding for international research collaborations, networks and alliances in different sizes and scope. Options ranging from collaborations among scientists as well as collaborations between professionals from science, industry and society are available. The funding schemes for research consortia often include thematic requirements, which have focussed primarily on economic development and recently on, so-called, grand challenges. From the perspective of individual researchers, this landscape is already quite complex, offers multiple career trajectories, albeit with the need to plan well in advance, with low funding rates providing little security, and with new framework programmes shifting thematic priorities regularly.

The full scope of organizing principles is also present on the national level, with programmes oriented along career steps, project size and/or research constellation. The variety of possible combinations and structuring principles becomes most evident when looking at diversified research systems, such as Germany and Switzerland; both with university and non-university research institutions as well as industrial research. Here, different funding schemes public and private, for basic and applied research - complement and overlap each other. The national research funding organizations provide career oriented personal grants for multiple career stages and with or without additional personnel; for the Swiss National Science Foundation (SNSF) programmes such as Ambizione or Prima and for the German Research Foundation (DFG) the Emmy Noether Programme. There are also a variety of funding options for single projects (e.g. Project Funding at SNSF or Project Proposals at DFG) as well as for research collaborations with smaller consortia (e.g. Research Training Groups at DFG or Sinergia at SNSF) up to thematical- 
ly specific clusters, that embody national research priorities (e.g. Collaborative Research Centres at DFG or National Centres of Competence in Research at SNSF). In addition, a small number of funding programmes address the institutional structure of the whole national research systems, for which applicants need to be institutions such as universities and for which the development of the funding programmes as well as the funding decisions happen in close collaboration with representatives from politics (e.g. National Research Programmes at SNSF or Excellence Initiative at DFG).

In between, several bi- or mulitlateral funding schemes exist, in which two or more national funding agencies cooperate to foster international collaboration (e.g. Open Research Area for the Social Sciences at DFG or Bilateral Programmes at SNSF). Furthermore, some of the national funding programmes are not restricted to applicants from that country, while some of the international funding programmes have restrictions with respect to nationalities. Even though we mentioned only part of the funding programmes from the EU and two countries $(\mathrm{D}, \mathrm{CH})$ and even excluded programmes from private foundations, what emerges is a picture of the European funding landscape that has become increasingly complex. From the perspective of science policy, the development of this landscape is one in which large funders (predominantly the EU) set the tone through their major programmes with smaller or national funders adjusting their programmes accordingly, sometimes to avoid duplications, sometimes to imitate, sometimes to fill gaps, and sometimes to innovate. The landscape is, thus, not just complex but dynamic. From the perspective of individual scientists, this complexity offers various strategies to move from one funding programme to the next, albeit with the issues of an increasing reliance on third-party funding, decreasing success rates for most funding programmes, and changing criteria for eligibility. From both perspectives, individual and policy, the question has become relevant, how funding programmes intertwine nationally and internationally. Since most of these funding programmes rely on some form of expert reviewing, the issue of how the variety of peer review procedures and formats interrelate should be crucial.

Peer review procedures mirror the diversity of research funding programmes in attempts to balance the specific scientific and political requirements; i.e. the principal aims of public research funding, to assure the quality as well as the legitimacy of funding decisions, are implemented through each peer review procedure. In the wake of growing science funding from the public sector, ongoing criticism of peer review deficits, and concerns about the over- 
load of reviewers, peer review formats are not just increasingly scrutinized for improvements, but efforts to formalize and innovate formats have become more frequent. Funder are testing variants and combinations of individual and/or panel review formats, with a notable shift towards panels of experts that meet locally to reach decisions, sometimes even in the course of on-site visits. Recent examples at the DFG are the review procedures for Collaborative Research Centres (Olbrecht 2014) and Clusters of Excellence (Möller et al. 2012); at the ERC it is 'Remote Evaluations' for ERC Grants (ERC 2018: 10; Luukkonen 2012: 10). For the increasingly complex and multi-stage peer review procedures, the role of a moderator or facilitator has been introduced, e.g. in the form of 'rapporteurs' (Collaborative Research Centers at DFG), or procedural observers (EU-COST). Procedural innovations also take place when new funding programmes are created or funding objectives change, e.g. the review procedure of the German excellence strategy had to be adapted for 2018 when a new object of evaluation - consortia of whole universities - was introduced. A further trend is the formalized and detailed collection of digital information about projects and applicants mostly through online platforms. This would enable, at least in principle, to assess the quality of applicants and their research projects separately. For highly complex proposals, e.g. for large consortia, combining different forms of expertise during reviewing is a declared goal. However, innovations and the increasing complexity of review procedures also need to be weighed against the tendency to formalize parts of procedures or to substitute them with measurable performance indicators.

In light of such trends, a first and rough classification of peer review procedures can take the size of proposals and cluster them into two groups: a) single project grants, individual (career) grants or fellowships, research groups under one principal investigator, and b) collaborative project grants, research consortia, large-scale institutional funding programmes. The size of proposals is a good first basis for classification as the complexity of review procedures seems to increase with the size of grants.

a) Peer review assessing proposals for single projects often proceeds in twosteps: First, the scientific quality and research potential of the proposed project is reviewed by external reviewers (commonly 2 or 3 ) or a reviewing panel, assembled by the funder. The reviewers give recommendations on eligibility and quality, sometimes complemented by a rating or even feedback to improve the proposal. Second, a decision taking body, such as the principal board of the funding agency, decides on the basis of these reviews, frequently 
in light of a whole group of proposals submitted to a deadline or within a time window. This can include prompts for applicants to adjust or change parts of the proposal, often associated with cuts in funding. When the funding programme is focussed on individual careers, the review procedure has additional elements. Those can involve more and sometimes additional external reviewers (e.g. ERC grants: Van den Besselaar et al. 2018: 315ff; Luukkonen 2012: 5ff.). Increasingly, oral presentations by applicants followed by a discussion with the reviewing panel are added.

b) Larger, collaborative projects are commonly submitted jointly by several applicants and are made up of different subgroups and subprojects, thus requiring more complex peer review procedures. The quality of the individual subprojects must be taken into account, in combination with their meaningful interaction within an overall research topic as well as their integration into a concept for (interdisciplinary) collaboration. Due to the larger size, such proposals need to be evaluated within a larger context, such as a whole research field or a national research system. Criteria and expertise for reviewing can become broad and include such diverse aspects as scientific quality from multiple research fields, leadership capabilities of principal investigators, local institutional setting, or even administrative feasibility. Peer review procedures respond to this increased complexity by a stronger division of labor. On the one hand, this is reflected in an expansion and greater differentiation of the roles of those involved in the peer review procedure. In some cases, the sub-projects are subjected to a separate review based on specialist expertise. Other reviewers then examine the overall design of the research network and, finally, the various assessments are brought together in a joint panel meeting or via compiling written reviews and comments in one document. On the other hand, the extended division of labor often results in further procedural steps and a pronounced multi-level nature of the procedure. In the case of large research consortia, evaluations may become even more complex, as proposals may be the result of long-standing network formations, with encompassing research agendas for multiple research organisations; all geared specifically towards the funding programme, e.g. for university alliances in national excellence initiatives.

\section{ELEMENTS OF REVIEWING PROCEDURES}

The purpose of the preceding chapter was to illustrate the diversity of contexts in which peer review for research funding is used. The adaptability of 
peer review to these different contexts and especially the increasing complexity leads us to think of peer review procedures not as something that has distinguishable types. The literature and practicioners sometimes suggest to distinguish, e.g., funding from editorial peer review, or external reviewing from panel reviewing. What we take from these national or supranational funding schemes is a number of elements that occur repeatedly and are combined to accommodate peer review procedures to specific contexts. We distinguish eight elements, as practices, that occur as purposeful activities in many peer review procedures and which combine to make up from simple to highly complex forms of peer review (the following draws from Schendzielorz \& Reinhart 2020).

1. Postulating activity: The submission of a grant proposal we conceive of as a request for approval of the related claims; the claim of eligibility of funding for a person, a project, a collaboration or even a consortium is to be understood as a request for acceptance of the proposal. These postulates create the cause for assessment, initiate and provide the need for an organized review procedure, and, ultimately, an evaluation-based funding decision.

2. Consultative activity: The processes in which a written proposal, and sometimes an oral presentation, is reviewed, we conceive of as a counselling practice. The written reviews, notes and verbally expressed estimations on the postulates are obtained as advisory expert opinions in order to assure a competent evaluation.

3. Decisive activity: The process in which a decision about acceptance or rejection is reached we conceive of as the decisive activity. Decisions can be based on grades, rankings, written notes, reviews, or oral presentations and are usually reached through the interaction of a designated group, i.e. an editorial board or a funding panel.

4. Administrative activity: The processes in which postulates are received and their treatment is launched and coordinated, we conceive of as administrative activity. This activity is usually provided by organizations that make use of peer review and is carried out by their members, such as managers or permanent staff of funding agencies. To define the administrative activity as a distinct practice takes account of the fact, that peer review procedures are executed under the premise of an existing organizational framework (funding agency, universities, or journals).

5. Debating activities: We conceive of the processes in which, the reviews, notes, and ratings, that contribute to the assessment are exchanged, com- 
mented, and discussed as debating activities. Debating can take place in reviewing panels and is not restricted to verbal exchanges but can contain written reviews, memos, notes, numerical ratings or votes, as well as verbal contributions.

6. Presenting activities: We conceive of processes in which the postulating applicants introduce themselves, present and explain their proposal, profile and their request in person, including answering related questions, as presenting activities. In these activities, the postulators are directly involved in the evaluation process. These activities occur in multi-level procedures e.g. for personalized grants as well as for project and collaborative project funding for instance during on-site visits. Most commonly they follow after an evaluation of written postulates.

7. Observing activities: The processes in which the assessment is monitored in order to control procedural compliance with regard to the respective tasks, rights and duties of each role, its course and the overall objective, we conceive of as observing activities. These activities are often combined with the obligation to document and/or to report on the reviewing procedure.

8. Moderating activities: Activities that regulate, moderate, explicate, and (re)explain the procedure to participants, we conceive of as moderating activities. The more complex and multi-leveled procedures become, the interplay of different activities needs to be explicitly concerted and aligned throughout, e.g. by explaining funding criteria to reviewers or by guiding participants from one procedural step to the next. This can also mean taking over as chairperson for panel discussions or presentations by applicants.

The different activities each correspond to specific tasks and responsibilities, some executed by different, some handled by the same persons but in separate phases of the procedure. Depending on the procedure, consultative, debating, moderating and decisive activities can be carried out one after the other by the same person, or they can be strictly separated. In the latter case, it is often the report of the observing activity that informs the decisively active ones about the results of consultation and discussion. The great variance of the peer review procedures in terms of effort and complexity is also due to the fact that all of the activities mentioned above can be done collectively, but hardly any of them necessarily require more than one person. Postulates can be submitted and presented collectively or individually according to preference, disciplinary convention or funding programme. The administrative, moderating and observing activities are often performed according to the 
thematic scope (narrow or broad), the length and complexity of the procedure, the quantity of the postulates to be treated and the available resources. Consultation usually results in multiple reports to obtain a variety of perspectives and debating activities, in which different voices are brought into conversation and weighed against each other, and is necessarily collective.

Combining these elements, different (types of) peer review procedures fall between a minimum and a maximum procedure:

\begin{tabular}{l|l} 
Minimum & Maximum (minimum + add-ons) \\
\hline Postulate & Discussion \\
Administration & Presentation \\
Consultation & Moderation \\
Decision & Observation
\end{tabular}

The minimum procedure consists of four elements: a postulating, an administrative, a consultative and a decisive activity. That a peer review procedure must have a submission (postulate), reviewing (consultation), and a decision should be a given. As peer review, especially when it is used to decide on public research funding, is always embedded in an organizational framework e.g. a funding agency or a university (see Neidhardt 2016: 271, Reinhart 2012) the minimum procedure must contain some form of administration, providing capacities and personnel to request and receive postulates, as well as to initiate, coordinate, and complete the review procedure.

The spectrum's other pole is marked by a maximum procedure composed of up to eight elements. It can mostly be found in funding programmes that aim at long-term and/or large-scale consortia. In addition to the four basic elements, debating activities, presenting activities, observing activities and moderating activities are added to the procedures. In very complex reviewing procedures some of the eight elements may be used more than once, e.g. when panel discussions are used at multiple stages (Collaborative Research Centers at DFG, for instance).

The systematic differentiation of types along activities allows thinking of peer review as a modular system. Such a view can help reframing key issues, both practical and theoretical, in a different light. With respect to the initial claim that peer review balances issues of, both, quality and legitimacy, questions can be raised as to which of the elements address just one or both of these issues. For practical purposes, the elements can be seen as a toolbox from which elements can be drawn, implemented, changed, or substituted to make 
peer review fit to specific contexts. Thus, the various types of peer review procedures, ranging from minimalist to maximalist forms, can be used to address diverse demands from different publics, including not only the scientific community and politicians, but also the citizens (as taxpayers) in all their diversity (age, race, ethnicity, religion, social, cultural and professional). Hence the complexity of procedures and their elaborate design are also determined by pressures for legitimacy with regard to questions of equality, diversity and inclusion as well as with regard to the size of grants.

While procedures can be complex and the needs to address very specific requirements can be predominant, we suggest thinking of what functions each element can provide. With respect to the main purposes of addressing quality and legitimacy, evaluation activities in science can generally serve at least six different functions (Hornbostel 2016). A knowledge function is provided by evaluation activities that generate information on the nature, impact and efficiency of the evaluated object. A control function is provided by activities that assure the procedural compliance and the congruence with respect to the central values, aims, and criteria of an evaluation process. A dialogue function is provided through activities that stimulate and promote communication in order to enable and improve mutual understanding among the evaluators but also between the evaluated and the evaluators. A legitimation function is provided by activities that justify decisions and provide accountability through reporting. An evidence function is provided by practices that use metaanalysis to ground decisions, which in peer review primarily comes from research on peer review. A public function is provided by activities that communicate evaluations to the public, e.g. in the form of rankings, ratings, or lists of funded proposals, with the combined effect of providing information and reputation (Hornbostel 2016: 245).

This functional differentiation allows discerning which function of a peer review procedure is fulfilled by which activity or combination of activities. The knowledge function, presumably the most important, requires a combination of several activities: postulating, consulting, presenting and debating can all be relevant here. Moreover, the mentioned activities also provide a dialogue function, where understandings and assessments are exchanged and negotiated, e.g. in individual reviews or in panel meetings. With respect to legitimacy, especially for the public, administrative, moderating and observing activities are crucial, serving to satisfy procedural compliance, reporting and accountability. These three activities - together with publicly available information on funding programmes, eligibility and procedures - ensure the 
control and the legitimation function. How the activities are compiled and (sequentially) aligned in a specific procedure may depend on context related requirements of quality and legitimation and, thus, lead to innovative ways of combining activities. For instance, it may depend on the demands and prioritization of the knowledge and the dialogue function which definitions of activities and their combinations are implemented.

Such an understanding allows to compile procedures according to the specific requirements and contexts, e.g. with regard to indigenous research. In case that the involvement of various groups of people and their representatives is of particular importance, the separation of roles and professionalized moderation as well as observation activities can provide functional frames to accomodate and negotiate competing interests and customs. Moreover, this modular conception of peer review opens up leeway for inventive variation and testing of diverse procedural constellations that may help to undercut traditional biases or power relations that prevail in decisions on public research spending.

\section{LEGITIMATION THROUGH PROCEDURE}

We are suggesting an alternative conception that systematically takes into account that grant peer review, especially for public research funding, is politicized. The variety of procedures, practices, and functions attest to the variety of contexts, in which peer review provides legitimation and not just assessments of scientific quality. This implies that peer review generates legitimation for its judgements on quality through the procedures by which these judgements are reached. What they provide is "legitimation through procedure" (Luhmann 1983). As such, the typology of practices and the idea of minimal or maximal procedural formats describes how various peer review procedures produce legitimacy through different combinations of activities. With respect to ensuring quality, the procedures ascribing great importance to consultative reviewing (most single project funding programmes) derive their quality assurance and legitimacy primarily from the written expert reviews and their subsequent discussion. Alternatively, the procedures that provide extensive time and space for presenting and debating activities, e.g. in panel assessments or on-site evaluations, complement the legitimation based on written expert judgement with discursive and deliberative activities. In that case, roles of observation and reporting are staffed separately or assigned to specifically trained personnel to assure procedural compliance. As 
such, they serve as a crucial source of legitimacy, because they are derived from deliberative standards of equal treatment, impartiality, equality of representation to reduce biases and discrimination.

The question of who takes over observing activities can then be of central relevance for legitimation, especially when the observational tasks overlap with other activities. One frequently used constellation uses staff or representatives of the funding agencies, who are partly also in charge of administrative activities, to perform observing and reporting activities. In the other frequent constellation, observational tasks are combined with moderating activities and are performed by scientists, who can be invited, elected, or recruited by the funding agency for these tasks, based on their experience in grant reviewing. In both cases the observing and reporting serves to ensure procedural compliance to improve the legitimation of the peer reviewing through procedure. Accordingly, an overlap of observing activities with consultative, debating or even decisive activities seems inappropriate regarding its potential to produce legitimation.

The potential for the different elements or activities to contribute to the legitimacy of the resulting decisions, is also predicated on who is tasked to perform them. The general expectation is that it should be mainly scientists, preferably experienced and eminent, to perform and head these activities; when this is the case, the scientific community will accept the decisions as legitimate, in most instances. When decisions are felt to be heavily mediated by politicians or administrators more criticism can be expected from within science. It seems that this general expectation has been waning recently and that the involvement, especially of administrators, is increasingly seen as a matter of course. The developing funding landscape, as presented in section 2 , relates to this presumably in two ways. First, the large number of funding programmes and the commonality of more complex reviewing procedures have made it necessary for reviewers, who are volunteering researchers, to rely on the professional expertise of administrators to navigate them through their tasks. Second, the shift towards competitive, project-based funding has led to programmes becoming more common that provide funding with specific aims, e.g. just for certain types of collaborations, just for certain research fields, or just for certain forms of societal impact, as opposed to more open programmes. Elements and criteria that make up the peer review procedures for such directed programmes are then specifically geared towards these funding aims and, as a result, the initiators and administrators become not 
just procedural but also thematic experts, with their direct involvement in consultation and decision then seen as beneficial.

In general, science policy agendas have become more important and influence what is considered good research. Quality based and legitimate decisions through peer review procedures are, thus not just relevant for specific funding programmes but are closely linked to the role of science in and for society (Brown 2009, Guston 2000, Jasanoff 2004; Kitcher 2011, Kitcher 2001). Assessments of scientific quality are increasingly articulated in terms of the potential (societal) usefulness of knowledge (Kaldewey 2013). Epistemic and practical qualities must be put in relation to each other, in such a form that scientific and societal impact can be seen as (possibly) consistent. Given the diverse quality and legitimation requirements for science in society, a double tension is emerging in science policy; roughly speaking, between basic and applied on the one hand and between excellent and robust on the other. The former extends as a continuum along the much-discussed distinction between autonomous and mission oriented research or basic research and application oriented research (Schmoch 2003; Wentland et al. 2012; Kaldewey/Schauz 2018), which is currently being renegotiated under the term translation (Macleod et al. 2014; Butler 2008; Blümel et al. 2015). The second tension unfolds between the poles of a small, highly specialized scientific group often described as excellent or elite, and the numerous scientifically trained and active scientific workers who cover the overall need for scientific work (Whitley 2000; Whitley et al. 2010). For negotiating these tensions the participation and integration of non-specialists or non-scientifists is a frequently suggested way forward (Sutter 2005). We think that such negotiations should be framed within the adaptable format of peer review procedures, where relating epistemic with political issues in science happens not in an abstract and mostly conceptual form, but with specific proposals to decide upon within a procedural framework.

\section{FUNDING POLICY AND THE PRACTICE OF REVIEWING}

We have argued that the increasing usage of peer review over a considerable time period is due, on the one hand, to the adaptability and scalability of peer review procedures, allowing for context specific implementations. On the other hand, the growth in directed, project-based, and competitive funding has created a greater need for peer review procedures to balance quality and legitimacy at the science-policy interface. The frequent criticism on a num- 
ber of specific deficits of peer review, both with respect to its effectiveness and its efficiency, should be seen less as grounds for abolishing peer review and more as a sign that it has become a central piece in the (self-)governance of science. As a consequence, most of the debates at the science-policy interface must touch on peer review in one way or another, making peer review an arena for deliberation. The literature on peer review has had little to say so far on how the practical issues around peer review can be addressed in light of this changed situation. Criticism of bias, low reliability, and low validity are increasingly substituted by calls for responsiveness to principles such as equity, diversity, and inclusion, as well as to requirements for participation, representation, and innovation. It has become clear, that peer review can no longer be treated as just a 'measurement device' for scientific quality. Its diversity attests to the fact that issues of quality and legitimacy are intertwined in peer review and should be addressed openly.

In order to make peer review responsive to calls for equity, diversity and inclusion as well as to participation, representation and innovation, the context of public research funding must rely on the principle of legitimation through procedure. In light of peer review criticism, the success of individual funding programmes is predicated less on whether peer review always identifies the best research and more on how funding decisions are reached through a procedure that is responsive and justified with respect to a wider variety of interests from stakeholders (among which scientists themselves will remain the most prominent). As a consequence, it becomes clear that how legitimation is produced through procedure depends on a balanced relation between the complexity of the procedure and an adequate separation of roles, division of labor and arrangement of procedural elements in peer review (Reinhart 2012). Considering the increasingly international collaborative, transdisciplinary and translational orientation of scientific research, this raises further questions regarding the design of peer review procedures: How can demands for responsiveness and participation be balanced with ongoing changes, both, in research practices and conceptions of what criteria for good research are?

While there are no ready-made or one-size-fits-all solutions for how to adjust peer review procedures to specific contexts, our typology of elementary practices in peer review offers a framework to think about responsiveness in a modular fashion and to experiment with one or multiple of these elements. In addition, a series of questions arise from our account that my help in adjusting and innovating peer review procedures, by putting them in a wider context: 
How do our funding programme and its peer review procedure fit into the national and international funding landscape? The most general issue here should be, whether eligibility criteria for the programme are unneccessarily narrow. In light of the emerging consensus that there is too much projectbased funding compared to block funding, narrow eligibility criteria will increase the complexity of the whole funding landscape. It will also lead to a more complex peer review procedure, as elements will have to be tweaked or added to satisfy the criteria of the programme.

How can we minimize the burden on applicants? Even though complaints about reviewer fatigue and reviewer scarcity have been more prominent, the burden on applicants in writing proposals and building profiles that suit specific funding programmes has increased disproportionally. Increasing rejection rates are the most prominent cause of this, as they put a higher burden on the group of (possible) applicants than on the group of (possible) reviewers. The 'easiest' solution - increasing approval rates by increasing the total amount of funding - is, obviously, anything but easy. Other possibilities could be: widening eligibility criteria (see above), increasing the duration of funding, simplifying submission formalities, shortening the time frame from submission to begin of funding, implementing flexible submission deadlines, or lowering administrative requirements during funding. Based on the ingenuity of funders, even smaller adjustments here could provide noticeable improvements for the large number of (possible) applicants.

How can we increase accessibility to our programme for diverse applicants and diverse research approaches? Openness and transparency of peer review have become key issues and relate to the responsibility and accountability of those organizing, counselling, and deciding in peer review. Making a distinction between publicity and legibility (Rosanvallon 2018) can be instructive in this context. While publicity refers to the availability of general information about a procedure in order to allow, for instance, applicants to know of a programme. Legibility refers to information that allows for a know how of the process of a programme. Ideally, it empowers diverse actors to competently play a part in peer review as a self-governing mechanism and diminishes historically grown asymmetries that often manifest in unequal power relations and tend to persist in modes of government. Legibility is the result of detailed information about how the process of peer review unfolds, preferably about ones own postulate, or the result of active participation in the process. In both cases, legibility leads to an understanding of the process and contributes to legitimation through procedure. Focussing on legibility may 
provide accountability while also offering an alternative to information overload and concerns about one-sided forms of control that result from unrestricted publicity.

How durable is the aim of our funding programme in terms of science policy? The science policy arena, both nationally and internationally, produces a diverse set of concepts, initiatives, and strategies that inform funding programmes, but that may only be relevant for a short period of time or may have conflicting goals between them. Calls for, e.g., inter- and transdisciplinarity, responsible research and innovation, disruptive innovation, open science, translation, etc. may not all be equally sound as a basis for funding programmes. Peer review procedures can reflect the durability of science policy agendas by adjusting, adding, or innovating elements to add sustainability when warranted. A more progressive step toward policy issues would be to actively include policy actors and societal stakeholders in certain elements of the peer review procedure, e.g. in discussion, observation, or even decision. Ideally, the peer review procedure would become an arena for policy deliberation and development, albeit limited within specific elements to avoid complete politization of the programme. This may even provide a basis for funders to be more active in science policy outside of specific funding programmes.

How can we experiment and innovate (on a smaller scale)? Radically reinventing how peer review, or an alternative procedure (e.g. a lottery), balances quality and legitimacy may be too ambitious. While funders are sometimes criticized for being too conservative in their programmes and reviewing procedures, that criticism tends to misjudge the actual diversity of procedures as well as the available room for change, when both scientific and political interests have to be met. Adjusting or adding individual elements of a procedure, however, may be possible in many situations and can be used for strategic goals; e.g. experimenting with the combination and the sequence of the different modes of consulting and debating activities, be it through individual reviews followed by discussions or through individually or jointly prepared panel peer reviews. As mentioned above, since non-scientists are increasingly playing an active and accepted role in reviewing procedures, funders can experiment with procedural elements to build up (in-house) expertise for specific aspects of quality and legitimacy; e.g. adding moderation activities with a focus on inclusion or diversity across multiple programmes can become a field of expertise for a funding organization, or adding observation activities that are combined with peer review research can build up expertise 
in monitoring of procedures as well as in setting standards or best practices for research funding in general.

One implication for all of these questions is that funders embrace an even more active role in science policy. Finding answers to these questions will mean to organize peer review procedures more deliberately, at the risk of higher administrative costs and possible criticism from within science. However, if the picture we painted in sections 2 and 3 is accurate, the funding landscape has already changed in ways to put funders in a position to be more active with respect to their reviewing procedures and with respect to science policy.

\section{B I B L I O G R A P H Y}

Baldwin, M. (2018) 'Scientific Autonomy, Public Accountability, and the Rise of "Peer Review" in the Cold War United States', Isis, 109(3), pp. 538-558. doi: 10.1086/700070.

Becher, T. and Trowler, P. (2001) Academic tribes and territories: Intellectual enquiry and the culture of disciplines. 2nd ed. Philadelphia: Open University Press.

van den Besselaar, P. and Sandström, U. (2015) 'Early career grants, performance, and careers: A study on predictive validity of grant decisions', Journal of Informetrics, 9(4), pp. 826-838. doi: 10.1016/j.joi.2015.07.011.

van den Besselaar, P., Sandström, U. and Schiffbaenker, H. (2018) 'Studying grant decision-making: a linguistic analysis of review reports', Scientometrics, 117(1), pp. 313-329. doi: 10.1007/s11192-018-2848-x.

Biagioli, M. (2002) 'From Book Censorship to Academic Peer Review', Emergences: Journal for the Study of Media \& Composite Cultures, 12(1), pp. 11-45. doi: $10.1080 / 1045722022000003435$

Blümel, C. et al. (2015) 'In search of translational research.' iFQ-BIH-Report. Berlin Institute of Health.

Brown, M. B. (2009) Science in democracy: expertise, institutions, and representation. Cambridge, Mass: MIT Press.

Butler, D. (2008) 'Translational research: Crossing the valley of death', Nature, 453(7197), pp. 840-842. doi: 10.1038/453840a.

Cole, S., Cole, J. R. and Simon, G. A. (1981) 'Chance and consensus in peer review', Science, 214(4523), pp. 881-886.

Guston, D. H. (2000) Between politics and science: assuring the integrity and productivity of research. Cambridge区; New York: Cambridge University Press.

Guthrie, S., Ghiga, I. and Wooding, S. (2017) 'What do we know about grant peer review in the health sciences?', F1000Research, 6.

Hornbostel, S. (2016) '(Forschungs-)Evaluation', in Simon, D. et al. (eds) Handbuch Wissenschaftspolitik. Wiesbaden: Springer Fachmedien Wiesbaden, pp. 243260. doi: 10.1007/978-3-658-05455-7_20.

Jasanoff, S. (2004) States of knowledge: the co-production of science and social order. London; New York: Routledge. 
Kaldewey, D. (2013) Wahrheit und Nützlichkeit: Selbstbeschreibungen der

Wissenschaft zwischen Autonomie und gesellschaftlicher Relevanz. Bielefeld: transcript.

Kaldewey, D. and Schauz, D. (2018) Basic and applied research: the language of science policy in the twentieth century. New York/Oxford: Berghahn Books.

Kitcher, P. (2001) Science, Truth, and Democracy. Oxford University Press. doi: 10.1093/0195145836.001.0001.

Kitcher, P. (2011) Science in a democratic society. Amherst, N.Y: Prometheus Books.

Luhmann, N. (2013) Legitimation durch Verfahren. 9. Auflage. Frankfurt am Main: Suhrkamp.

Luukkonen, T. (2012) 'Conservatism and risk-taking in peer review: Emerging ERC practices', Research Evaluation, 21(1), pp. 48-60. doi: 10.1093/reseval/rvs001.

Macleod, M. R. et al. (2014) 'Biomedical research: increasing value, reducing waste', The Lancet, 383(9912), pp. 101-104. doi: 10.1016/S0140-6736(13)62329-6.

Möller, T., Antony, P., Hinze, S. \& Hornbostel, S. (2012) Exzellenz begutachtet. Befragung der Gutachter in der Exzellenzinitiative. Berlin (iFQ-Working Paper, 11). http://www.forschungsinfo.de/Publikationen/Download/working paper_11_2012.pdf.

Neidhardt, F. (2016) 'Selbststeuerung der Wissenschaft durch Peer-ReviewVerfahren', in Simon, D. et al. (eds) Handbuch Wissenschaftspolitik. Wiesbaden: Springer Fachmedien Wiesbaden, pp. 261-277. doi: 10.1007/9783-658-05455-7_22.

Neufeld, J., Huber, N. and Wegner, A. (2013) 'Peer review-based selection decisions in individual research funding, applicants' publication strategies and performance: The case of the ERC Starting Grants', Research Evaluation, 22(4), pp. 237-247. doi: 10.1093/reseval/rvt014.

Olbrecht, M. (2014) Entscheidungsfindungsprozesse von Gutachtergruppen. https://edoc.hu-berlin.de/handle/18452/17598

Reinhart, M. (2012) Soziologie und Epistemologie des Peer Review. Baden-Baden: Nomos.

Rosanvallon, P. (2018) Die gute Regierung. Berlin: Suhrkamp Verlag.

Schendzielorz, C. and Reinhart, M. (2020) 'Die Regierung der Wissenschaft im Peer Review / Governing Science Through Peer Review', dms - der moderne staat - Zeitschrift für Public Policy, Recht und Management, 13(1). https://www.budrich-journals.de/index.php/dms/article/view/35458

Schmoch, U. (2003) Hochschulforschung und Industrieforschung: Perspektiven der Interaktion. Frankfurt/Main囚; New York: Campus.

Shapin, S. (1994) A Social History of Truth: Civility and Science in SeventeenthCentury England. University Of Chicago Press.

Shapin, S. and Schaffer, S. (1985) Leviathan and the Air-Pump: Hobbes, Boyle, and the Experimental Life. Princeton University Press.

Sutter, B. (2005) 'Von Laien und guten Bürgern. Partizipation als politische Technologie', in Bogner, A. and Torgersen, H. (eds) Wozu Experten? Ambivalenzen der Beziehung von Wissenschaft und Politik. Wiesbaden: VS Verlag für Sozialwissenschaften, pp. 220-240. doi: 10.1007/978-3-322-80692$5 \_11$.

Wentland, A. (ed.) (2012) Forschen in getrennten Welten: Konkurrierende Orientierungen zwischen Wissenschaft und Wirtschaft in der Biotechnologie. Baden-Baden: Nomos. 
Whitley, R. (2000) The intellectual and social organization of the sciences. 2nd ed. Oxford University Press.

Whitley, R., Gläser, J. and Engwall, L. (eds) (2010) Reconfiguring knowledge production: changing authority relationships in the sciences and their consequences for intellectual innovation. Oxford University Press.

Zuckerman, H. and Merton, R. K. (1971) 'Patterns of Evaluation in Science: Institutionalisation, Structure and Functions of the Referee System', Minerva, 9(1), pp. 66-100. 